\title{
Isolated Systemic Supply to Normal Lung-A Rare Cause for Hemoptysis (A Case Report with Review of Literature)
}

\author{
Rengarajan Rajagopal ${ }^{1}$ Gurpreet S. Gulati ${ }^{1}$ \\ ${ }^{1}$ Department of Cardiovascular Radiology and Endovascular \\ Interventions, All India Institutes of Medical Sciences, New Delhi, \\ India
}

J Clin Interv Radiol ISVIR 2018;2:62-68

\begin{abstract}
Address for correspondence Rengarajan Rajagopal, MD, DNB, Department of Cardiovascular Radiology and Endovascular Interventions, Room No. 10A, CN Centre, All India Institutes of Medical Sciences, New Delhi, India 110029

(e-mail: heraghava@gmail.com).
\end{abstract}

\author{
Abstract \\ Keywords \\ - bronchopulmonary \\ malformation \\ - malinosculation \\ - isolated systemic sup- \\ ply to normal lung \\ - hemoptysis \\ - sequestration \\ - trans arterial \\ embolization \\ - vascular plug
}

The authors report the case of a 23-year-old man with hemoptysis who had an abnormal retrocardiac opacity in the medial aspect of the left lower lobe on a chest radiograph. Contrast-enhanced computed tomography (CT) revealed anomalous systemic arterial supply to the left lower lobe with absence of pulmonary arterial branches to the involved lung. The patient underwent successful transarterial embolization of the systemic supply without any complications. Follow-up imaging showed persistent complete thrombosis of the artery. He recovered with no symptoms at 6 months.

\section{Introduction}

Isolated systemic arterial supply to a normal lung lobe (ISSNL) is a rare congenital cause of hemoptysis. Patients are usually asymptomatic, with the anomalous vessel detected on a routine chest radiograph as an abnormal retrocardiac opacity. The other common presentations are with hemoptysis, dyspnea on exertion, cardiac failure, and cardiac murmur detected on clinical examination. Recently transarterial embolization (TAE) has been used as a minimally invasive procedure for treatment of these patients, in contrast to traditional surgical techniques that include ligation of the anomalous vessel with or without lobectomy or segmentectomy. This manuscript details the case of a 23-year-old patient with ISSNL who underwent TAE and recovered well postprocedure, along with a review of previously reported cases.

\section{Case Report}

A 23-old-year man, nonsmoker, was referred with complaints of insidious onset of multiple episodes of hemoptysis $(200-$ $300 \mathrm{~mL}$ each) for the past 1 year. The bleeding was with minimal effort and not associated with cough, chest pain, or dyspnea. There was no history of tuberculosis or bleeding from other sites. On examination, breath sounds were equal on both sides of the chest with no added sounds. Routine blood investigations were normal with normal coagulation parameters. Dengue serology was negative. Chest radiograph showed an abnormal vessel-like opacity in the retrocardiac region on the medial aspect of the left lower lobe, which was nontapering with no dichotomous branching and was not converging toward the pulmonary hilum ( - Fig. $\mathbf{1}$ ). On suspicion of a pulmonary arteriovenous malformation (AVM), a computed tomographic (CT) pulmonary angiogram received

August 6, 2017. accepted after revision

February 1, 2018.
Copyright (C2018 by Indian Society of Vascular and Interventional Radiology
License terms

(우 (1) $\ominus \circledast$ 
was performed. It showed attenuated pulmonary arterial branches to the left lower lobe with no arteriovenous fistulae ( - Fig. 2a). On the delayed images of the CT scan, an aberrant vessel arising from the descending thoracic aorta was seen to supply the basal segments of the left lower lobe (-Fig. 2b). The patient was counseled about the various treatment options including conservative, surgical, and endovascular management. He opted for endovascular embolization.

A right transfemoral venous access was obtained, and pulmonary angiograms were performed to demonstrate the pulmonary arterial (PA) anatomy of the left lower lobe and for PA pressure measurements (-Fig. 3). The PA pressures were normal. The proximal segments of the left pulmonary

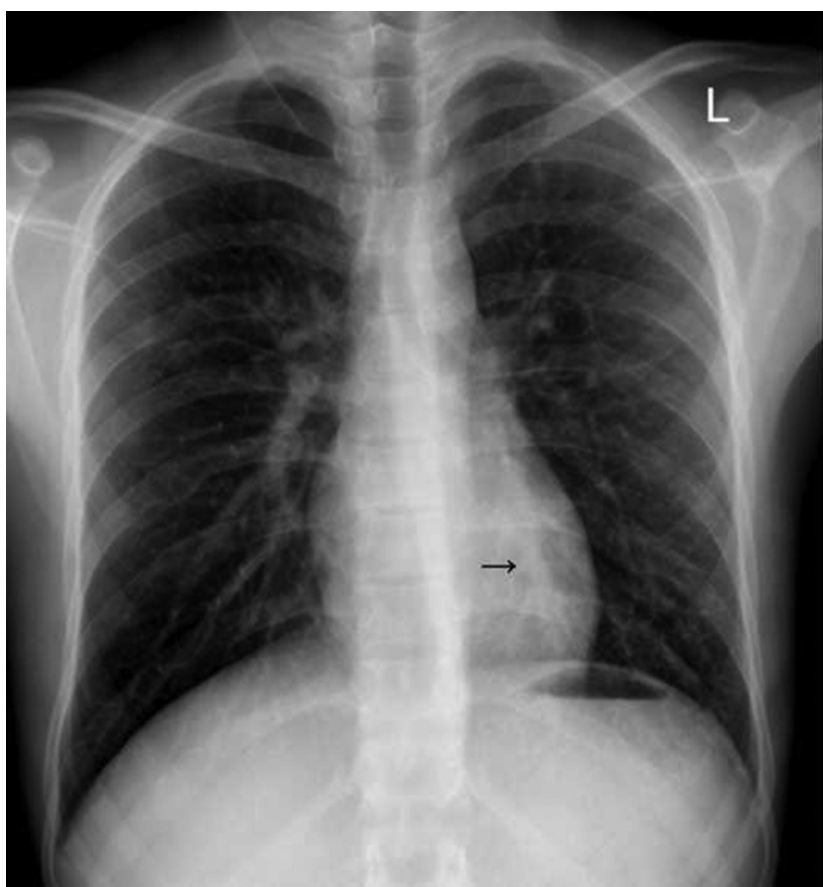

Fig. 1 Chest radiograph of a 23-year-old patient with abnormal retrocardiac vessel-like opacity in medial aspect of left lower lobe. artery branches to the basal segments of the left lower lobe were attenuated with absence of parenchymal blush (indirect evidence of absence of PA supply). Following this, an aortogram was performed through the femoral arterial access, to demonstrate the aberrant vessel that showed no stenotic or aneurysmal segments (-Fig. 4a). The venous drainage was by the left inferior pulmonary vein into the left atrium. A long sheath was then placed into the aberrant vessel in preparation for deploying the vascular plug.

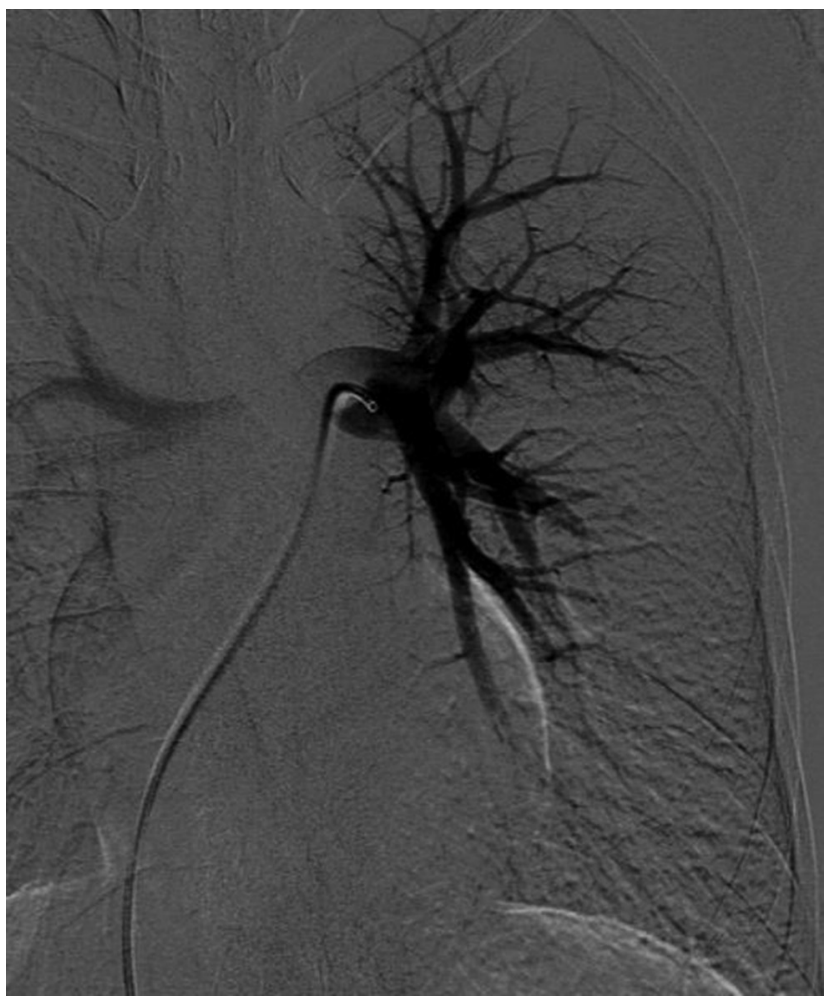

Fig. 3 Angiogram of the left pulmonary artery showing attenuated proximal segment of branches to basal segments of lower lobe with absence of parenchymal blush.

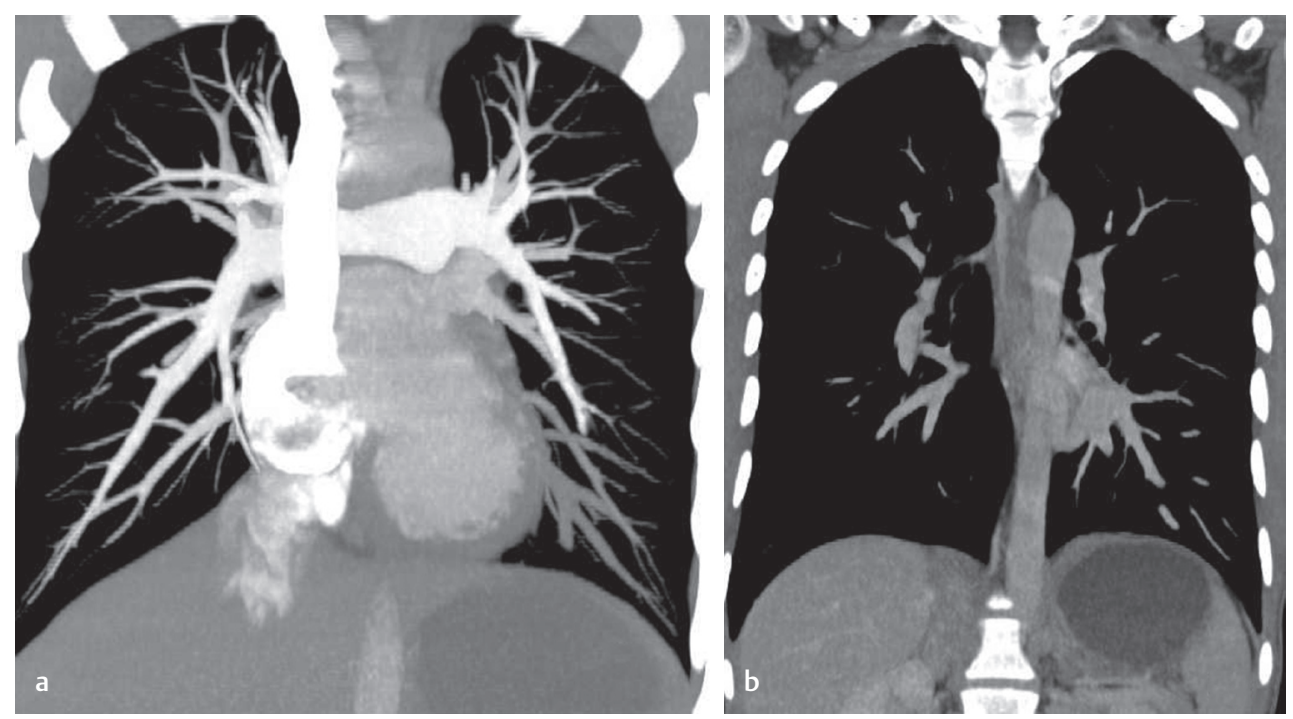

Fig. 2 Computed tomography pulmonary angiogram showing attenuated pulmonary arterial branches to the left lower lobe (a) and the delayed-phase image showing abnormal vessel from the descending thoracic aorta supplying the basal segments of left lower lobe (b). 

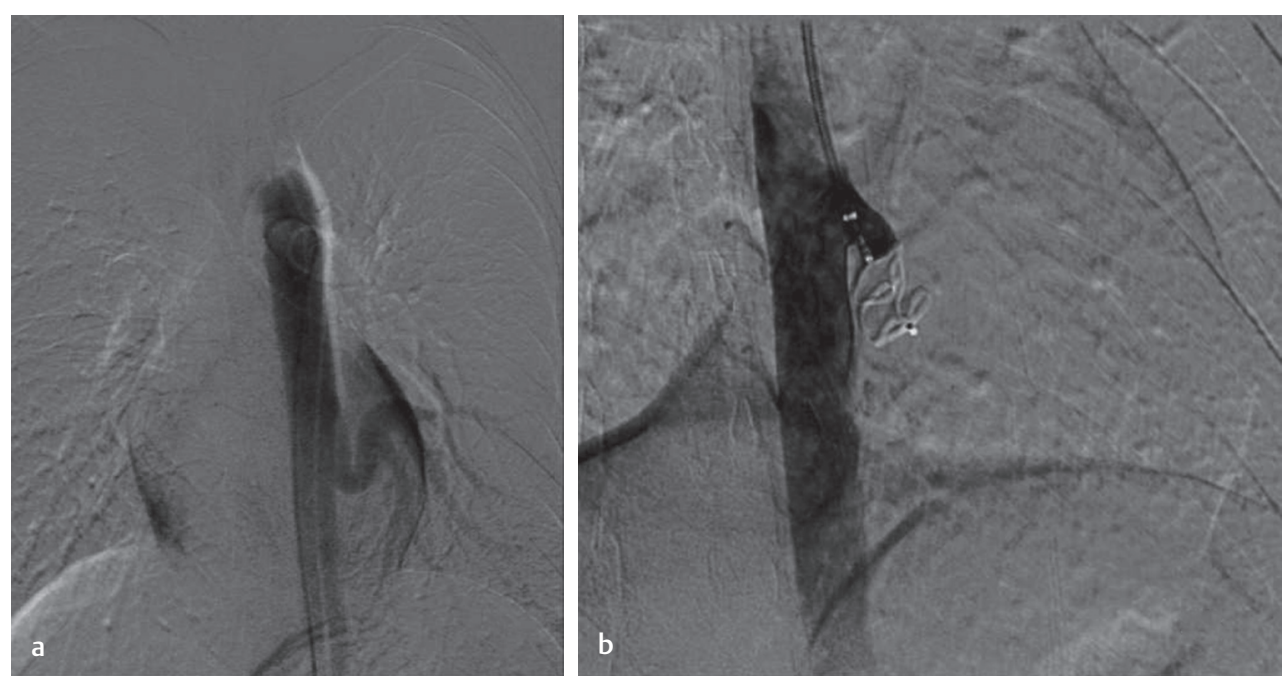

Fig. 4 Aortogram demonstrating the aberrant vessel from the DTA (a) and angiogram showing complete thrombosis of the vessel after deployment of Amplatzer vascular plug II (b).

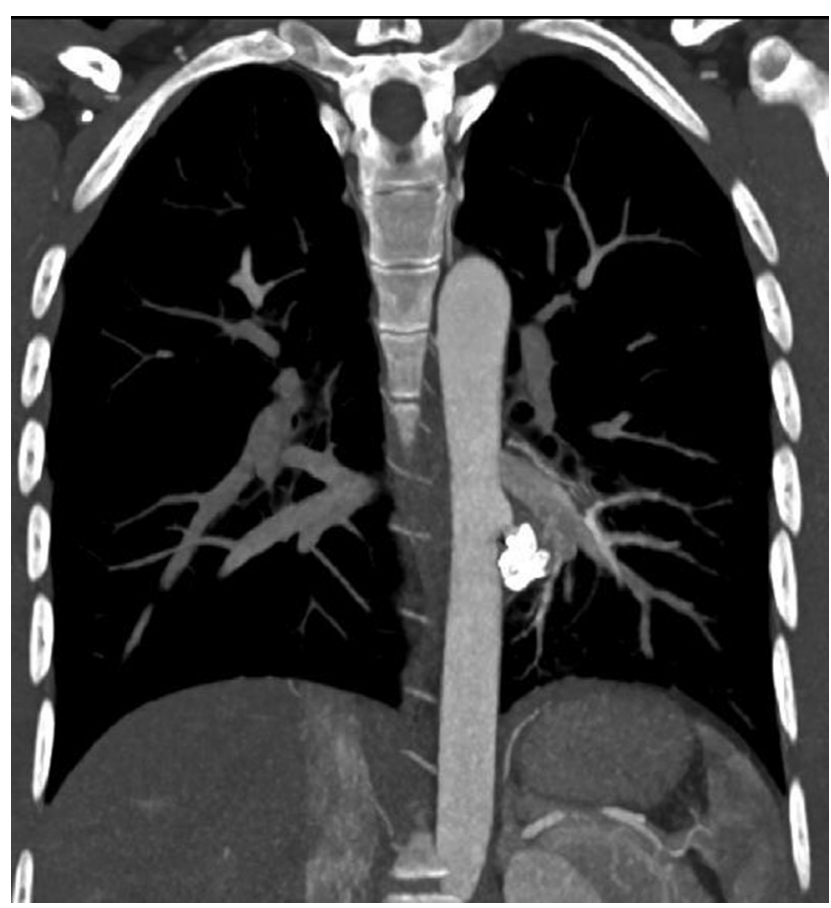

Fig. 5 Computed tomography aortic angiogram at 1-month follow-up showing persistent complete thrombosis of the aberrant vessel.

As a stable, selective position of the sheath could not be achieved, a left transbrachial arterial access was then obtained. Through this, a long sheath (Flexor $90 \mathrm{~cm} 6 \mathrm{~F}$, Cook Medical) was placed into the descending limb of the aberrant vessel. A vascular plug of size $14 \mathrm{~mm}$ (Amplatzer AVP II, unconstrained length $10 \mathrm{~mm}$, AGA Medical Corporation) was deployed through the sheath ( - Fig. $\mathbf{4 b}$ ) after confirmation of correct positioning by oblique angiograms. Sheath angiograms after 10 minutes showed complete occlusion of the aberrant vessel with absence of blush.

The patient was started on intravenous antibiotics and analgesics. Chest radiograph done on postprocedure day 1 did not show any opacity. The patient was discharged on the second postprocedure day. CT angiography done at 1-month follow-up showed complete thrombosis of the anomalous artery with no signs of pulmonary infarction seen in the involved lung (-Fig. 5). At 6 months of follow-up, the patient is asymptomatic with no complications.

\section{Discussion}

Isolated systemic arterial supply to a normal lung lobe is a type of bronchopulmonary vascular malformation. The latter term comprises a broad spectrum of congenital disorders that may involve abnormalities of one or a combination of three components, namely the airway and lung parenchyma, arterial supply, and the venous drainage, with or without associated defects in the diaphragm. The term "sequestration" was first coined by Pryce in 1946 to describe an abnormal segment of the lung that was disconnected from the normal bronchial tree and had systemic arterial supply. ${ }^{1}$ He further classified different such variations into three types, depending on whether the systemic artery supplied the normal or abnormal lung, which were later modified by Sade. The term "malinosculation" was first introduced by Clements and Walter in 1987 to describe a spectrum of anomalies characterized by abnormal communications between the lung parenchyma and airways, arteries and veins. This spectrum of malinosculations was further refined by Lee, giving a step-wise systematic approach for classification of bronchopulmonary vascular malformations.

Lee's system classifies bronchopulmonary vascular malformations into seven types based on isolated or concurrent presence of abnormalities of various components ( - Table $\mathbf{1}$ ). The first three types represent isolated anomalies of the airway, arterial, or venous components respectively, whereas the remaining are mixed malformations. This systematic approach for identification of all components helps in correct diagnosis (in contrast to multiple syndromes used for nomenclature) and planning appropriate treatment. 
Table 1 Lee's system of classification of bronchopulmonary vascular malformations ${ }^{2,3}$

\begin{tabular}{|c|c|c|}
\hline Type & Abnormality & Examples \\
\hline A & Isolated bronchial malinosculation & $\begin{array}{l}\text { Bronchogenic cyst } \\
\text { CPAM } \\
\text { Congenital lobar emphysema }\end{array}$ \\
\hline B & Isolated arterial malinosculation & $\begin{array}{l}\text { Isolated systemic supply } \\
\text { Dual supply } \\
\text { Interrupted pulmonary artery }\end{array}$ \\
\hline C & Isolated venous malinosculation & $\begin{array}{l}\text { Isolated Scimitar vein } \\
\text { PAPVC } \\
\text { TAPVC }\end{array}$ \\
\hline $\mathrm{D}$ & Mixed bronchoarterial malinosculation & Typical intralobar sequestration \\
\hline $\mathrm{E}$ & Mixed bronchovenous malinosculation & Combination of types $\mathrm{A}$ and $\mathrm{C}$ \\
\hline $\mathrm{F}$ & Mixed arteriovenous malinosculation & $\begin{array}{l}\text { Fistula between Scimitar's vein and systemic arterial } \\
\text { supply }\end{array}$ \\
\hline G & Mixed bronchoarteriovenous malinosculation & $\begin{array}{l}\text { Classic Scimitar's syndrome } \\
\text { Extralobar sequestration }\end{array}$ \\
\hline
\end{tabular}

Abbreviations: CPAM, congenital pulmonary airway malformation; PAPVC, partial anomalous pulmonary venous connection; TAPVC, total anomalous pulmonary venous connection.

Isolated systemic arterial supply to a normal lung lobe (Lee type $B$ malinosculation-without associated airway abnormality or sequestration, previously Pryce type 1 sequestration) is a rare congenital abnormality. ${ }^{1}$ It is thought to result from persistence of intersegmental arterial plexus that connect the embryonic dorsal aorta to the pulmonary parenchyma, along with arrested PA growth. ${ }^{4,5}$ These anomalous arterial branches are distinct from the normal bronchial arteries. The lobar branches of the pulmonary artery supplying the involved segment of lung are absent or attenuated. The venous drainage of the involved segment is by the corresponding pulmonary veins (which may be dilated) into the left atrium, with no direct communication between the systemic artery and the pulmonary artery or vein. The parenchymal density of the affected lobe on CT may be increased, which is likely due to congestion (due to systemic pressures) and associated alveolar hemorrhages ${ }^{6,7}$ This anomaly has been reported in the Asian population with an increased incidence (> 90\% of reported cases are Asian patients), suggesting a probable genetic etiology. ${ }^{8}$ However, further studies are needed to confirm this association.

The usual pattern of isolated arterial malinosculation is an anomalous vessel supplying the left lower lobe, as is seen in our patient, which is seen arising from the descending thoracic aorta usually between T8 and T11 vertebral levels., ${ }^{910}$ The involvement of the upper and middle lobes, as well as right lung involvement, is uncommon. The anomalous vessel can also be seen to originate from the celiac trunk, abdominal aorta, and subclavian and internal mammary arteries. Very rarely, there may be multiple feeding arteries. ${ }^{11}$ The anomalous branches may not withstand high systemic pressures due to predominant elastic lamina (unlike muscular arteries) and hence tend to bleed, presenting as hemoptysis. ${ }^{12}$ The high pressures may also cause thickening and calcification of the wall of the anomalous artery with aneurysm formation and development of stenosis, especially in elderly patients., .13
Focal pulmonary hypertension may develop with subsequent cardiac failure.

Patients are usually asymptomatic. Hemoptysis is the most often complaint in symptomatic cases. Dyspnea on exertion and heart failure resulting from the left to left shunt is uncommon. On clinical examination, the patient may have a continuous murmur in the left chest mimicking a patent ductus arteriosus. Abnormal retrocardiac vessel-like density with striated margins obliterating a portion of the aorta as seen on the chest X-ray may be suggestive of the diagnosis. ${ }^{9}$ These abnormal vessels do not follow the pulmonary pattern of branching (dichotomous and tapering toward the periphery) and do not converge at the pulmonary hilum. Absence of normal lower lobar pulmonary artery shadow in the left hilar region, increased interstitial markings, and obliteration of the aortic interface are other pointers toward the diagnosis. ${ }^{14}$ The diagnosis is usually confirmed by CT or magnetic resonance angiography (MRA).

Isolated systemic arterial supply to a normal lung lobe should be differentiated from other causes of systemic arterial supply to the lung in adult patients, including chronic inflammatory disorders, tuberculosis, collaterals in pulmonary artery obstruction, and pulmonary arteriovenous malformations. Scarring may be seen in the involved lung parenchyma in chronic inflammation, whereas in ISSNL, the lung parenchyma is normal. Severe involvement of the pulmonary arteries by Takayasu's arteritis may result in their attenuation and consequent parasitization by systemic branches.

The traditional standard treatment offered to these patients is surgical, with satisfactory results. ${ }^{8}$ The surgical options include simple ligation of the anomalous supply, lobectomy or segmentectomy with resection of the anomalous artery, and switching the branch from the aorta to the pulmonary artery. Because the lung lobe supplied by the anomalous artery is normal, removal by lobectomy may be undesirable. TAE has recently evolved as a nonsurgical, minimally invasive, therapeutic option. There are several case 
Table 2 Reported cases of TAE in ISSNL in literature

\begin{tabular}{|c|c|c|c|c|c|}
\hline Author and year & $\begin{array}{l}\text { Age and } \\
\text { sex }\end{array}$ & History & Embolic agent & Complications & $\begin{array}{l}\text { Follow-up } \\
\text { period }\end{array}$ \\
\hline $\begin{array}{l}\text { Izzillo et al } \\
(2000)^{16}\end{array}$ & $34 \mathrm{M}$ & Hemoptysis & Metallic coils & $\begin{array}{l}\text { Transient pulmonary } \\
\text { infarction }\end{array}$ & $2 y$ \\
\hline $\begin{array}{l}\text { Huang et al } \\
(2005)^{12}\end{array}$ & $3 \mathrm{mo} \mathrm{F}$ & $\begin{array}{l}\text { Respiratory distress and } \\
\text { heart murmur }\end{array}$ & Metallic coils & $\mathrm{Nil}$ & $6 \mathrm{mo}$ \\
\hline $\begin{array}{l}\text { Huang et al } \\
(2005)^{12}\end{array}$ & $13 \mathrm{~F}$ & $\begin{array}{l}\text { Hemoptysis and mitral } \\
\text { regurgitation }\end{array}$ & Metallic coils & $\mathrm{Nil}$ & $18 \mathrm{mo}$ \\
\hline $\begin{array}{l}\text { Saida et al } \\
(2006)^{17}\end{array}$ & $41 \mathrm{~F}$ & Recurrent hemoptysis & Metallic coils & Chest pain & $6 y$ \\
\hline $\begin{array}{l}\text { Lim et al } \\
(2009)^{18}\end{array}$ & $26 \mathrm{M}$ & Hemoptysis, chest pain & Metallic coils & $\mathrm{Nil}$ & $6 \mathrm{mo}$ \\
\hline $\begin{array}{l}\text { Abe et al } \\
(2010)^{6}\end{array}$ & $24 \mathrm{~F}$ & Hemoptysis & Metallic coils & Chest pain & $1 \mathrm{y}$ \\
\hline $\begin{array}{l}\text { Canyigit et al } \\
(2011)^{7}\end{array}$ & $53 \mathrm{M}$ & Chest pain & $\begin{array}{l}\text { Metallic coils and } \\
\text { AVP II }\end{array}$ & $\begin{array}{l}\text { Chest pain, cough, Pulmo- } \\
\text { nary infarction }\end{array}$ & $10 \mathrm{mo}$ \\
\hline \multirow[t]{4}{*}{ Jiang S, $(2011)^{13}$} & $33 \mathrm{~F}$ & Recurrent hemoptysis & Metallic coils & Mild chest pain & $2 y$ \\
\hline & $28 \mathrm{M}$ & Recurrent hemoptysis & Metallic coils & Nil & $20 \mathrm{mo}$ \\
\hline & $24 \mathrm{~F}$ & $\begin{array}{l}\text { Recurrent hemoptysis } \\
\text { and exertional dyspnea }\end{array}$ & AVP I & Mild chest pain & $8 \mathrm{mo}$ \\
\hline & $19 \mathrm{M}$ & $\begin{array}{l}\text { Recurrent hemoptysis } \\
\text { and cough }\end{array}$ & Metallic coils & $\mathrm{Nil}$ & $7 \mathrm{mo}$ \\
\hline $\begin{array}{l}\text { Anil et al } \\
(2012)^{19}\end{array}$ & $23 \mathrm{M}$ & Recurrent hemoptysis & $\begin{array}{l}\text { Metallic coils, NBCA } \\
\text { glue }\end{array}$ & $\mathrm{Nil}$ & $6 \mathrm{mo}$ \\
\hline $\begin{array}{l}\text { Gümüstas et al } \\
(2013)^{20}\end{array}$ & $20 \mathrm{M}$ & Recurrent hemoptysis & Metallic coils & Nil & $18 \mathrm{mo}$ \\
\hline $\begin{array}{l}\text { Sugihara et al } \\
(2013)^{21}\end{array}$ & $67 \mathrm{~F}$ & $\begin{array}{l}\text { Abnormal shadow on } \\
\text { chest X-ray }\end{array}$ & $\begin{array}{l}\text { Metallic coils (with } \\
\text { balloon occlusion) }\end{array}$ & Nil & $12 \mathrm{mo}$ \\
\hline \multirow[t]{4}{*}{$\begin{array}{l}\text { Mammen et al } \\
(2015)^{15}\end{array}$} & $19 \mathrm{~F}$ & Recurrent hemoptysis & $\begin{array}{l}\text { AVP II, metallic coils, } \\
\text { NBCA glue ( } 80 \%)\end{array}$ & $\mathrm{Nil}$ & $5 \mathrm{mo}$ \\
\hline & $32 \mathrm{~F}$ & Recurrent hemoptysis & Detachable balloons & Recanalization & $6 \mathrm{mo}$ \\
\hline & $27 \mathrm{M}$ & Recurrent hemoptysis & Metallic coils & $\begin{array}{l}\text { Recurrent hemoptysis at } \\
10 \text { mo }\end{array}$ & $1 \mathrm{y}$ \\
\hline & $15 \mathrm{M}$ & Recurrent hemoptysis & AVP II & $\mathrm{Nil}$ & $6 \mathrm{mo}$ \\
\hline $\begin{array}{l}\text { Machida et al } \\
(2017)^{22}\end{array}$ & $80 \mathrm{M}$ & $\begin{array}{l}\text { Chest murmur, abnormal } \\
\text { shadow in X-ray }\end{array}$ & Metallic coils & $\mathrm{Nil}$ & $3 \mathrm{mo}$ \\
\hline Our case (2017) & $23 \mathrm{M}$ & Recurrent hemoptysis & AVP II & Chest pain & $6 \mathrm{mo}$ \\
\hline
\end{tabular}

Abbreviations: AVP, Amplatzer vascular plug; F, female; ISSNL, isolated systemic supply to normal lung; M, male; NBCA, N-butyl cyanoacrylate; TAE, transarterial embolization.

reports of patients with ISSNL, who have undergone successful TAE with no major complications, with the added advantage of decreased periprocedural morbidity as compared with open surgery. Various embolic agents have been used including detachable balloons, metallic coils, vascular plugs, and glue. Vascular plugs have recently replaced metallic coils as they can be precisely deployed in high-flow vessels with comparatively lesser chance of migration, and they can be repositioned before complete deployment. The device is oversized by approximately 20 to $40 \%$ for secure fitting and total occlusion. The anomalous vessel in our patient was embolized with a vascular plug with $20 \%$ oversizing.

Complications of TAE include lung infarction, secondary infection, migration of the embolic material to nontarget areas, and incomplete embolization due to collateral feeders. Lung infarction and ischemic changes have been rarely reported after TAE in ISSNL, and this is likely due to collateral supply from various adjacent arteries that include bronchial, inferior phrenic, and intercostal arteries. ${ }^{13}$ Lung necrosis has been reported in one patient after TAE, who was subsequently treated by surgical ligation of the anomalous artery. However, no other major complications after TAE have been reported in literature. Minor complications such as chest pain and subsegmental atelectasis resulting from infarction have been reported. ${ }^{13,15}$ Our patient experienced minimal chest pain in the postoperative period, which was relieved with anti-inflammatory medications. Recanalization is a possibility, as seen in patients with pulmonary AVM who undergo TAE with vascular plug embolization. Recurrence of hemoptysis may occur in these patients due to development of 
collateral bronchial supply. Hence patients who receive embolization require long-term follow-up by contrast-enhanced CT scans. ${ }^{6,13}$ The follow-up CT scan in our patient after 1 month showed complete thrombosis of the aberrant vessel. The patient is asymptomatic at 6 months follow-up.

\section{Conclusion}

Isolated systemic supply to a normal lobe of the lung is one of the rare congenital bronchopulmonary malformations, which presents with hemoptysis. TAE of the anomalous artery is safe and effective without any major complications, as is seen in our patient and other reports in literature (-Table 2). There is no consensus regarding the ideal embolic agent. Vascular plugs are being increasingly used, due to the ability to deploy them precisely.

\section{Conflicts of Interest}

None.

\section{Informed Consent and Ethics Committee Approval}

The patient provided informed written consent for publication of the clinical material.

\section{Funding}

Nil.

\section{References}

1 Pryce DM. Lower accessory pulmonary artery with intralobar sequestration of lung; a report of seven cases. J Pathol Bacteriol 1946;58(3):457-467

2 Lee M-L, Lue H-C, Chiu I-S, et al. A systematic classification of the congenital bronchopulmonary vascular malformations: dysmorphogeneses of the primitive foregut system and the primitive aortic arch system. Yonsei Med J 2008;49(1):90-102

3 Lee ML, Tsao LY, Chaou WT, et al. Revisit on congenital bronchopulmonary vascular malformations: a haphazard branching theory of malinosculations and its clinical classification and implication. Pediatr Pulmonol 2002;33(1):1-11

4 Clements BS, Warner JO. Pulmonary sequestration and related congenital bronchopulmonary-vascular malformations: nomenclature and classification based on anatomical and embryological considerations. Thorax 1987;42(6):401-408

5 Ellis K. Fleischner lecture. Developmental abnormalities in the systemic blood supply to the lungs. AJR Am J Roentgenol 1991;156(4):669-679

6 Abe T, Mori K, Shiigai M, et al. Systemic arterial supply to the normal basal segments of the left lower lobe of the lungtreatment by coil embolization-and a literature review. Cardiovasc Intervent Radiol 2011;34(Suppl 2):S117-S121

7 Canyigit M, Gumus M, Kilic E, et al. Aneurysm of an anomalous systemic artery supplying the normal basal segments of the left lower lobe: endovascular treatment with the Amplatzer Vascular Plug II and coils. Cardiovasc Intervent Radiol 2011;34(Suppl 2):S126-S130

$8 \mathrm{Wu} \mathrm{KA}, \mathrm{Wu} \mathrm{CP}$, Perng WC. Ethnicity relation to anomalous systemic arterial supply to normal basal segments of the left lower lobe. Clin Imaging 2008;32(6):477-479

9 Miyake H, Hori Y, Takeoka H, Takuma M, Kawagoe T, Mori H. Systemic arterial supply to normal basal segments of the left lung: characteristic features on chest radiography and CT. AJR Am J Roentgenol 1998;171(2):387-392

10 Campbell DC Jr, Murney JA, Dominy DE. Systemic arterial blood supply to a normal lung. JAMA 1962;182:497-499

11 Akiba T, Marushima H, Kamiya N, et al. Anomalous systemic arterial supply to the basal segments of the lung with three aberrant arteries. Gen Thorac Cardiovasc Surg 2012;60(2):118-121

12 Huang SM, Weng KP, Lin CC, et al. Systemic arterial supply to the normal basal segments of the left lower lobe-a safe alternative to surgery. Acta Cardiol Sin 2005;21:121-126

13 Jiang S, Shi JY, Zhu XH, et al. Endovascular embolization of the complete type of anomalous systemic arterial supply to normal basal lung segments: a report of four cases and literature review. Chest 2011;139(6):1506-1513

14 Kim TS, Lee KS, Im JG, Goo JM, Park JS, Kim JH. Systemic arterial supply to the normal basal segments of the left lower lobe: radiographic and CT findings in 11 patients. J Thorac Imaging 2002;17(1):34-39

15 Mammen S, Keshava SN, Moses V, Chiramel GK, Irodi A, Gnanamuthu BR. Endovascular treatment of isolated arterial pulmonary malinosculation. Indian J Radiol Imaging 2015;25(3):239-243

16 Izzillo R, El Hajjam M, Qanadli S, et al. [Intralobar sequestration of the lung in an adult (type 1 of Pryce). Treatment by coil embolization] [in French]. J Radiol 2000;81(9):996-999

17 Saida T, Ninomiya H, Hojo F, Nakayama M, Yamauchi T, Saida Y. Systemic arterial supply to the normal basal segments of the left lower lobe treated by coil embolization, with long-term follow-up. Radiat Med 2006;24(5):365-368

$18 \mathrm{Lim} \mathrm{HH}$, Huh JK, Kim JH, et al. Therapeutic embolization of systemic arterial supply to normal basal segments of the left lower lobe of the lung. Respirology 2009;14(4):606-608

19 Anil G, Taneja M, Tan A-G-S. Endovascular treatment of isolated systemic arterial supply to normal lung with coil and glue embolisation. Br J Radiol 2012;85(1012):e83-e86

20 Gümüştaş S, Akça A, Ciftçi E, Topçu S, Akgül AG. A minimal invasive surgical alternative to aberrant systemic arterial supply: coil embolization. Interv Med Appl Sci 2013;5(1):34-38

21 Sugihara F, Murata S, Uchiyama F, et al. Transcatheter arterial embolization of anomalous systemic arterial supply to the basal segment of the lung. Acta Radiol Short Rep 2013;2(7):2047981613511363

22 Machida Y, Motono N, Matsui T, Usuda K, Uramoto H. Successful endovascular coil embolization in an elder and asymptomatic case of anomalous systemic arterial supply to the normal basal segment. Int J Surg Case Rep 2017;34:103-105 